Abdel-Kader, M. and Dugdale, D. (1998), Investment in Advanced Manufacturing Technology: A Study of Practice in Large UK Companies, Management Accounting Research, Vol. 9, pp. 261-284. ISSN 1044-5005. doi:10.1006/mare.1998.0071 Definitive version available online at: http://www.sciencedirect.com/science/journal/10445005

\title{
Investment in Advanced Manufacturing Technology: A Study of Practice in Large UK Companies
}

\author{
Magdy G. Abdel-Kader \\ Faculty of Commerce, Cairo University, Giza 12613, EGYPT
}

(Corresponding author)

Email: Magdy.Kader@brunel.ac.uk

David Dugdale

Bristol Business School, University of the West of England, Bristol, Frenchay Campus, Bristol

BS16 1QY, UK

Acknowledgement: The authors would like to thank Professor R. W. Scapens, two anonymous reviewers and participants at the BAA conference (Birmingham, March 1997) for their valuable comments on earlier drafts of this paper.

\begin{abstract}
This paper reports the results of a survey investigation into the investment decision making practices of large UK manufacturing companies, especially in relation to investments in advanced manufacturing technologies. A $24 \%$ response rate was received in a survey of the finance directors of 466 large UK manufacturing companies. Responses were classified into three groups ranging from non-users of AMT to sophisticated users and analysis revealed that more sophisticated users do emphasise certain intangible benefits in combination with measures relating to the traditional dimensions of return and risk.
\end{abstract}

Key words: Advanced Manufacturing Technology (AMT); capital investment decision; survey; intangible factors.

\section{Introduction}

This paper reports the results of a survey investigation into the investment decision making practices of large UK manufacturing companies. The interest of the researchers was in the manner in which companies justify investment in advanced manufacturing technologies (AMT) and whether the methods used are significantly different from those used in justifying non-AMT investments.

Slagmulder et al. (1995) highlighted strong interest in the topic, perhaps because investment in Computer-integrated Manufacturing (CIM) technologies such as Computer-aided Manufacturing (CAM) , Flexible Manufacturing Systems (FMS) and Automated Storage and Retrieval Systems (AS/RS) can develop manufacturing capabilities that create or sustain competitive advantage.

The literature can be divided into three strands. First there are a large number of surveys of practice such as those of Klammer et al (1991) in the USA, Pike and Wolfe (1988) in the UK, Van Cauwenberg et al. (1996) in Belgium, and Kalyebara (1996) in Australia. These have concentrated particularly on the measures of financial performance and project risk used in 
practice. Most survey studies deal with capital budgeting decisions in general and relatively few with AMT decisions in particular. However, the surveys of Pike et al. (1989) and Slagmulder et al. (1995) were exceptions and these studies highlighted the importance of non-financial or 'intangible' factors in AMT decision making.

A second strand of research can be traced back to Haynes and Solomon (1962), Hastie (1974) and King (1975). These researchers have gained insights through field studies of practice. They point out that much of the capital budgeting literature places great emphasis on the appraisal of investments. However, in practice, investment decisions involve many steps, of which appraisal is only one, and possibly not the most important. These researchers emphasise other steps such as the creation of investment proposals, their progress through the organisation, the interplay of financial and 'strategic' information in the process etc. More recent field studies by Slagmulder and Bruggeman (1992) and Nixon (1995) concentrated on AMT investment decision making. Their conclusions echo those of the earlier field studies, emphasising all the stages in the capital budgeting process and the importance of "strategic" (as opposed to purely financial) considerations in AMT decision making.

A third strand of research can be described as 'normative', developing prescriptions for practice. Whereas the first two strands are broadly descriptive: identifying practice either through questionnaire surveys or field studies, this strand emphasises the development of theoretical models. This work has a long history, from the development of the return on investment (ROI) measure to the discounted cash flow measures of net present value (NPV) and internal rate of return (IRR). Subsequently, the rapid development of finance theory has seen the relationship between return and risk theorised and empirically tested (see for example: Lumby, 1995; Davis and Pointon, 1994; and Pike and Dobbins, 1986).

During the 1980s a number of researchers focused on the alleged difficulties of justifying AMT investment proposals against the, by then traditional, return-risk theoretical framework. Kaplan and Atkinson (1989) provided a powerful analysis in which they identified excessively high hurdle rates, incorrect base-case forecasts and failure to recognise all the benefits of AMT as deficiencies in traditional appraisal methods when applied to AMT investments. Perhaps in response to Kaplan's (1986) question: 'Must AMT be justified by faith alone?' Several researchers have developed theoretical models which combine both financial and non-financial variables and Slagmulder et al. (1995) note: 'More and more authors are convinced that good investment appraisal requires that strategic and financial considerations be reconciled and integrated'.

The increasingly rich literature supplies many possible theoretical models and suggestions as to how AMT investment decisions 'should' be taken. The particular aim of this research was to test a number of hypotheses and assumptions which are endemic, either implicitly or explicitly, in the existing literature. These are developed in the next section.

\section{Development of Hypotheses}

In this section a number of hypotheses will be developed that postulate relationships between several investment variables (the dependent variables) and level of AMT investment (the independent variable). Table 1 provides a summary of the dependent variables.

While some authors, (e.g. Primrose and Leonard , 1987 and Park and Son, 1988) suggest that all the costs and benefits of AMT investments should be quantified financially and others (e.g. Medearis et al., 1990 and Elango and Meinhart, 1994) suggest that strategic considerations might totally over-ride financial ones, the majority (e.g. Meredith and Suresh, 1986; Srinivasan and Millen, 1986; Parsaei and Wilhelm, 1989; O’Brien and Smith, 1993; Accola, 1994; Angelis and Lee, 1996) opt for a combination of financial and strategic considerations in AMT appraisal. Meredith and Hill (1987) suggest a relationship between the appropriateness of traditional financial analysis and strategic analysis in evaluating an investment. They suggest that traditional 
financial analysis is most appropriate when evaluating stand-alone systems while strategic analysis becomes most appropriate in evaluating fully integrated systems (see also: Meredith and Suresh, 1986 and Slagmulder et al., 1995).

These considerations lead to the following two hypotheses:

H1: Companies rely more on strategic decision criteria for AMT investments than for nonAMT investments.

H2: Less reliance is placed on financial analysis for AMT investments than for non-AMT investments.

Many authors (e.g. Putrus, 1990; Datta et al., 1992; O’Brien and Smith, 1993; and Accola, 1994) have made various assumptions about the 'intangible' or 'strategic' benefits that are associated with AMT investments. The 'normative literature', especially, is replete with theoretical analyses that include throughput, market share/growth, flexibility, quality, organisational learning, company image, human factors, workforce morale, technology position and other benefits of AMT.

H3: A wide range of intangible benefits become important in the justification of AMT (as opposed to non-AMT) investment.

The use of capital budgeting techniques such as payback (PB), return on investment (ROI), and discounted cash flow (DCF) methods has been a major subject in almost every previous survey. DCF methods have been classified as 'sophisticated' while PB and ROI have been seen as 'unsophisticated' or 'naive' (e.g. Klammer et al., 1991; Pike, 1988; Chen, 1995). Generally, surveys have reported increasingly widespread use of sophisticated, DCF, methods with a preference for internal rate of return (IRR) over net present value (NPV) (Klammer et al., 1991; Pike, 1988 and 1996). However, the payback period method is still the most widely used evaluation technique with virtually all companies using it either as a primary or secondary technique (Lefley, 1994). Previous surveys found a significant relationship between company size and the use of sophisticated investment appraisal methods such as NPV and IRR with the largest companies usually using the most sophisticated method(s) (e.g., Schall et al., 1987; Drury et al., 1993; and Chen, 1995). In the survey reported here, large companies were sampled, so:

H4 : Sophisticated, DCF, methods of investment appraisal are now more important than unsophisticated methods in large companies.

Just as large companies tend to use more sophisticated techniques it might be expected that companies investing in more advanced forms of AMT might employ more sophisticated investment appraisal techniques. Indeed, Woods et al. (1985, p. 42) had expected that ' $\ldots$ users (of new technology), by definition, are more advanced in their thinking and therefore more likely to use more modern investment appraisal techniques with their greater sophistication ...'

H5: The sophistication of the financial evaluation technique used increases with the sophistication of the investment project being evaluated: from non-AMT to fully integrated AMT.

In addition to 'financial' and 'strategic' considerations, evaluation of AMT projects, like other investment opportunities, needs to take account of project risk. Two approaches are usually considered: the moment-oriented approach and the dimension-oriented approach (see, for example, Accola et al., 1995; Accola, 1994; Aschenbrenner, 1984; and Schoemaker, 1979). The moment-oriented approach assumes that data are available to identify the multiple possible project outcomes and their related probabilities. In this approach, the riskiness of an investment project may be measured by its standard deviation or variance. The dimension-oriented approach presumes that project risk can be analysed in different dimensions. For example, Accola (1994) suggested: impact on company liquidity; variability of project outcomes; and possibility of massive (ruinous) loss. In recommending a dimension based approach, Accola (1994) argued that risk adjustment of the hurdle rate or payback period to take account of risk was suspect 
because this confounded two intrinsically different project characteristics: return and risk. The following hypothesis is set to test the applicability of Accola's suggestion:

H6: Practitioners consider three risk 'dimensions' to be important: impact of the project on company liquidity, variability of project outcomes, and possibility of massive loss.

Moment-oriented approaches to risk measurement are usually classified into two categories (Ho and Pike, 1991; 1992; and Walker and Klammer, 1984). Simple (naive) techniques involve intuitive adjustments to either the cash flows or a parameter in the evaluation model. For example, increasing the discount rate, reducing the required payback, or using conservative cash flow forecasts. Sophisticated techniques, on the other hand, are based on comprehensive evaluation of uncertainties and include probability analysis, simulation, and the capital asset pricing model (CAPM). Where researchers (e.g. Meredith and Suresh, 1986 and Hundy and Hamblin, 1988) have commented on the risk associated with AMT investments, they have assumed that such investments, because of their large outlays, long lives, delayed benefits and possibly unfamiliar technology are more risky than other investments.

H7: More sophisticated treatments of risk are employed in the evaluation of AMT as opposed to non-AMT investments.

Underpinning much of the existing literature is a presumption that traditional, economic/financial investment appraisal measures systematically penalise AMT investment proposals (see, for example, Kaplan, 1986; Kaplan and Atkinson, 1989, ch. 12; Dugdale and Jones, 1995; and Abdel-Kader, 1997). First, traditional, financial, analysis, it is argued, fails to capture many of the 'intangible' benefits which should flow from AMT investment. Second, traditional approaches militate against AMT because of high discount rates and short payback targets which systematically penalise long-term investments.

H8: The same financial criteria are applied to AMT investments as other (non-AMT) investments.

H9: AMT investments are difficult to justify because of failure to recognise all their "strategic" or "intangible" benefits.

The development of hypotheses is summarised in table 2.

\section{Research design and data collection}

The survey instrument was designed to identify differences between the evaluation of AMT and other types of investment and to investigate any relationship between the sophistication of investments themselves and the sophistication of the technique(s) used to evaluate them. Of particular interest was the impact of qualitative factors on AMT decisions and how practitioners incorporate such intangible factors into their analysis. An attempt was therefore made to identify and investigate all the qualitative factors previously reported in the literature.

Respondents were asked to rate the importance of each technique or criterion on a five-point rating scale. Previous surveys indicate that most companies use more than one technique, so it was logical to gather information about the importance of each technique rather than to categorise or rank them. However, to provide information comparable with previous surveys, respondents were also asked to identify the financial appraisal technique they regarded as most important if the firm used several techniques.

While previous studies have compared practices relating to different project types (replacement, expansion, etc.), no attention has been paid to distinguishing between AMT investments and other types of investment. A particular feature of this survey is the division of responding companies into three groups: those not employing AMT; those using less integrated forms of AMT and those using fully integrated AMT systems. This division facilitated relatively sophisticated statistical analysis. As noted by Chen (1995), most previous surveys have been analysed using only simple descriptive statistics but here, Kruskal-Wallis one-way ANOVA was 
used to compare the importance of various techniques and criteria across each group of companies. The Kruskal-Wallis one-way ANOVA is a non-parametric statistical test for repeated measures and three or more mutually independent samples (see, for example, Gibbons, 1993 and Siegel and Castellan, 1988).

The survey was structured so as to identify the extent of AMT investment in the responding firm, the techniques employed to measure financial return and risk when evaluating investment opportunities and the "intangible" variables considered. The grouping of companies according to their commitment to AMT allowed comparative analysis of the return, risk and intangibles dimensions. The survey also sought the opinions of practitioners on the expected benefits of AMT investments and the difficulties they experienced in obtaining approval for AMT investments.

A postal questionnaire was used to collect primary data. This method was chosen in order to access a sufficiently large number of respondents without incurring undue costs. The questionnaire was developed during September 1995 - January 1996 and involved study of the literature and pilot interviews with finance directors of three UK manufacturing companies in order to ensure that the final version was not easily misunderstood and of manageable length.

A sample of 466 UK manufacturing companies were chosen from the 'FAME' database (Financial Analysis Made Easy). These companies satisfied two criteria: (1) the first digit of their primary SIC UK industry codes are either ' 3 ' or ' 4 ' ${ }^{1}$ so that they operate in the manufacturing sector, and (2) they are large companies so that they are more likely to have invested in AMT. The size of companies was measured by three variables: turnover (a minimum of $£ 30$ million for the year ended 1994), fixed assets (a minimum of $£ 30$ million for the year ended 1994) and number of employees (a minimum of 100 employees for the year ended 1994). Based on these criteria, questionnaires were mailed to the financial directors of 466 large UK manufacturing companies during the last week of January, 1996 and follow-up telephone calls were made to non-respondents in the last week of February, 1996. By the end of March 138 responses were received, a response rate of $29.6 \%$. Of those received, 36 were returned unanswered because the company policy was not to respond to surveys (20 Companies), the questionnaire was not relevant to the company (8 companies), lack of time (5 companies), or the company was in the middle of a merger (3 companies). So, the net response rate was 23.7\% (102 completed questionnaires / 430 potential respondents). Further, three completed questionnaires were judged as not valid to the analysis because the respondents had not participated in investment evaluation processes. Hence, 99 usable completed questionnaires were used in the analysis giving a net usable response rate of 23\% (99 / 430). This response rate is comparable with other similar surveys such as those of Lefley (1994) and of Chen (1995) which had response rates of 28.8\% and $20 \%$ respectively.

Follow-up interviews were carried out during April-June 1996 with nine of the respondents who had experience in AMT decisions making. These interviews enabled the reliability of questionnaire responses to be checked and allowed further investigation of some issues raised by the questionnaire results.

In order to assess the possibility of any sample bias the 99 responding companies were compared with the sample frame of 466 companies. The comparison was based on the two criteria for choosing the original sample, the industry distribution (according to the first digit of

\footnotetext{
${ }^{1}$ The first digit of ' 3 ' includes metal goods, engineering and vehicles industries while the first digit of ' 4 ' includes other manufacturing industries
} 
SIC UK primary industry) and the size of the company measured by turnover, fixed assets, and number of employees for the year ending 1994.

The chi-square test of homogeneity indicated a significant difference between the industry distribution of the responding companies and the sample frame $(\mathrm{p}=.005)$ and a crosstabulation for the industry distribution of both samples suggested that responding companies might be biased towards SIC UK industry code ' 3 '. Two-sample t-tests were conducted on company size measured by turnover, fixed assets and number of employees for the year ended 1994. The results indicated that responding companies were significantly larger than the sample frame in terms of turnover $(\mathrm{p}=.007)$, but not significantly different in terms of fixed assets $(\mathrm{p}=.943)$ or number of employees $(\mathrm{p}=.981)$.

To further investigate the effect of non-response bias, the answers to the main questions in the questionnaire from respondents who replied without the follow-up telephone calls (72 respondents) were compared with the answers from respondents who replied only after the follow-up telephone calls (27 respondents). There was no significant difference between the two groups of answers ${ }^{2}$. Thus, it might be concluded that more respondents would not change the results of the study.

It can be concluded that non-response bias is not likely to be a threat to the conclusions of the study. However, the analysis indicates that the findings are more generalisable to larger rather than smaller companies and to companies with SIC UK primary code ' 3 ' rather than ' 4 '.

\section{Survey Results and Hypotheses testing}

\subsection{Classification of responding companies}

In order to test the research hypotheses, responding companies were categorised according to their level of AMT investment. Seven types of AMT system are frequently referred to in the literature: CNC, robotics, AMH, FMS, CAD, CAM and CIM and, following Meredith and Suresh (1986), these systems were categorised into three groups according to level of integration. The first level comprised stand-alone systems such as CNC and robotics, the second level comprised linked systems such as CAD, CAM, and AMH, and the third level comprised integrated systems such as FMS and CIM.

Seventy-six companies (77\%) had invested in AMT and table 3 shows that most of these had invested in several different AMT applications. The table shows that CAD systems were most prevalent while the relatively lowest percentages were for FMS and CIM. This categorisation permitted the operationalisation of the independent variable in the study, defined as 'degree of AMT investment' and ranging from none through stand-alone to fully integrated systems.

There were no companies in the "stand-alone" AMT group, so the companies were classified into three groups: non-AMT companies, less-integrated companies (those adopting CAD and/or CAM and/or AMH) and fully-integrated companies which have invested in FMS and/or CIM. Table 4 summarises the number and percentage in each group.

\subsection{The importance of financial return, intangibles and risk in AMT investment}

Most of the hypotheses developed postulate differences between the evaluation of non-AMT and AMT investments. (The exceptions are $\mathrm{H} 4$ and $\mathrm{H} 6$ that deal with practitioner attitudes to investment appraisal methods and risk measurement in general). In order to test the hypotheses responding companies were asked to rate the importance of 27 different factors/techniques in investment decision making. Responses are summarised in table 5 under four broad headings:

\footnotetext{
${ }^{2}$ For example, means differences in the importance of 'payback', 'quality and reliability of outputs' and 'sensitivity analysis' were $0.12(\mathrm{p}=.883), 0.10(\mathrm{p}=.834)$ and $0.20(\mathrm{p}=.318)$.
} 
financial appraisal techniques, non-financial criteria, risk analysis techniques and Accola’s risk aspects.

In table 5 the mean "score" for each factor/technique is shown separately for each category of respondents: non-AMT, less integrated and fully integrated. This analysis facilitated the use of a non-parametric analysis of variance (the Kruskal-Wallis test) in order to determine whether there were statistically significant differences in the AMT investment behaviour of the three groups of companies. The results of this test are summarised in table 6 .

Table 6 shows that there are no significant differences (at the 5\% level) among the three groups of companies as regards financial appraisal and risk analysis techniques. However, this is not the case for non-financial criteria. Here there are four criteria: 'quality and reliability of outputs' ( $\mathrm{p}$-value $=.0006)$, 'reduced lead-times' $(\mathrm{p}=.0045)$, 'obtaining greater manufacturing flexibility' $(\mathrm{p}=.0140)$, and 'reduced inventory levels' $(\mathrm{p}=.0398)$ which are significant. It can be concluded that the importance of these four non-financial criteria are affected by the level of AMT. All four criteria have higher degrees of importance in fully integrated companies than in less integrated companies while their importance in less integrated companies is greater than in non-AMT companies. There is thus evidence that these four 'strategic' criteria may be major reasons for investing in AMT and hypothesis 1, that companies rely more on strategic decision criteria in evaluating AMT, can be supported ${ }^{3}$.

The results do not support hypothesis 2: less reliance is placed on financial analysis for AMT investments than for non-AMT investments. While strategic analysis becomes more important for AMT companies this is not at the expense of financial analysis. Casual inspection of table 2 suggests that AMT companies see financial analysis as more important than do non-AMT companies. However, the Kruskal-Wallis test failed to reveal any significant differences in the behaviour of the three groups of companies and the null hypothesis (no difference between AMT and non-AMT companies) cannot be rejected.

Analysis of non-financial investment criteria (tables 5 and 6) does suggest that these factors become more important in AMT investment and significantly so in four cases: quality and reliability of outputs; greater manufacturing flexibility; reduced lead-times and reduced inventory levels. Additionally two factors: requirements of customers and consistency with corporate strategy were seen as important by all respondents with no significant differences between companies. The remaining factors were not so important, being relatively lowly rated by all respondents with no significant differences between companies. Hypothesis 3 is supported but the number of significant intangible benefits is restricted. Four such benefits were identified in this survey.

Hypothesis 4 relates to investment decision making in general and states: sophisticated, DCF, methods of investment appraisal are now more important than unsophisticated methods in large companies. However, on the basis of the sample of large companies surveyed, this hypothesis cannot be supported. With the exception of discounted payback, all the measures of financial performance were seen as important, with the unsophisticated methods (payback and ROI) rating marginally more important than the sophisticated, DCF, methods.

${ }^{3}$ Strictly, a hypothesis cannot be 'proved', it can only be rejected or supported. Here, the hypothesis is that there is a difference in reliance on strategic decision criteria across non-AMT, less integrated and fully integrated AMT companies. The test relates to the null hypothesis- that there is no difference across companies- and this null hypothesis is rejected. By inference the alternate hypothesis is supported. 
The results do not support hypothesis 5: the sophistication of the financial evaluation technique used increases with the sophistication of the investment project being evaluated. All the methods of appraisal, with the exception of discounted payback, were considered to be important and there were no significant differences in the behaviour of the three groups of companies. The null hypothesis cannot be rejected and it can be concluded that a "package" of financial return indicators is employed by most companies in appraising investment opportunities - whether investing in AMT or in more conventional projects.

The results are somewhat inconclusive in testing hypothesis 6: that practitioners consider the three risk 'dimensions': impact on company liquidity, variability of project outcomes, and possibility of massive loss to be important. Almost as many respondents regarded these issues to be relatively unimportant as thought them important or very important. Analysis of the results by type of company was also uninformative with the less- integrated group of companies rating these issues less important than either the fully integrated or the non-AMT groups of companies.

The results do not support hypothesis 7: that more sophisticated treatments of risk are employed in the evaluation of AMT investments. Only the relatively unsophisticated technique of sensitivity analysis was considered to be really important by any of the respondents and the “AMT companies” were just as reluctant to use sophisticated methods (such as simulation and the capital asset pricing model) as the non-AMT companies. The Kruskal-Wallis test did not reveal any significant differences (at 5\% level of significance) in the behaviour of the three groups of companies.

\subsection{Further analysis of financial return measures}

Respondents who use the payback method as a financial appraisal technique for evaluating investment projects were asked to indicate the required payback period which is most frequently used in their firms. Table 7 shows the percentages of respondents for each group of companies. A period of 3 years or less is most frequently used: $70 \%$ of the non-AMT companies, $76 \%$ of the less integrated companies, and $83 \%$ of the fully integrated companies require payback in 3 years or less.

Respondents who use discounting methods were asked to indicate the range of minimum rates of return or discount rate required by their firms, see table 8 . The modal band for non-AMT companies and less integrated companies was in the range $10-15 \%$ while it was in the range 16 - 20\% for fully integrated companies. The results indicate increasing discount rates from nonAMT companies to less integrated companies to fully integrated companies. In non-AMT companies $41 \%$ of respondents use a discount rate higher than $15 \%$ but the corresponding figures for less integrated and fully integrated companies are $53 \%$ and $60 \%$ respectively.

The results suggest that the more integrated AMT companies specify more stringent payback periods and hurdle rates. However, chi-square tests failed to reveal any significant difference in the behaviour of the three groups of companies and the null hypothesis (no difference between non-AMT and AMT companies) cannot be rejected.

The survey results appear to support hypothesis 8: the same financial criteria are applied to AMT as to other investments. (In fact visual inspection of tables 7 and 8 even suggests that financial criteria may become more stringent from non-AMT to less-integrated to fullyintegrated companies.) The typical payback periods in the range 1 - 3 years and discount hurdle rates of $10-16 \%$ or even more might be expected to penalise AMT investment proposals.

This evidence therefore appears to support these who argue that AMT investment proposals, with long lives and delayed benefits are penalised by the financial criteria used in their evaluation. However, caution must be exercised in drawing conclusions about hypothesis 8 because respondents were also asked whether they agreed with the following proposition: "It is difficult to get AMT investment proposals approved because of stringent financial criteria”. Only 
$15 \%$ of respondents agreed or strongly agreed with this statement, the vast majority were either neutral or disagreed, see table 9.

The conflicting results mean that hypothesis 8 is neither supported nor rejected.

\subsection{Further analysis of the benefits of AMT investment}

The practices of companies which invest in AMT were further investigated through a question which aimed to identify which factors they evaluated financially and which non-financially. A list of 21 benefits was provided and respondents were asked to identify whether each benefit was considered financially, non-financially or not at all in the evaluation process. The results are shown in table 10.

These results indicate that eight benefits are almost always considered, either financially or non-financially, in evaluating AMT investments: reduced material costs (100\%), reduced scrap and rework costs (100\%), improved product quality (100\%), reduced labour costs (98\%), reduced inventories level (98\%), faster response to market needs (97\%), improved competitive position (97\%), and reduced lead times (96\%). Conversely, a significant minority did not consider the following four benefits in the evaluation process at all: obtaining experience of new technology (45\%), effects on employee morale (40\%), floor space reduction (34\%), and reduced after sale costs (32\%).

Most firms were willing to quantify seven benefits in financial terms: reduced labour costs (97\%), reduced material costs (96\%), reduced inventories (92\%), reduced scrap and rework costs (89\%), increased sales volume (79\%), savings from less frequent set-ups (69\%), and increased manufacturing capacity (52\%).

The benefits which were considered on a non-financial basis by the majority of respondents were: improved product quality (86\%), faster response to market needs (86\%), consistency with corporate strategy (78\%), improved competitive position (77\%), greater manufacturing flexibility (75\%), reduced lead times (74\%), improved company image (71\%), easier production scheduling (65\%), retention of market share (58\%), and increased market share (54\%)

The results appear to support hypothesis 9: AMT investments are difficult to justify because of failure to recognise all their strategic or intangible benefits. The responses do indicate that some benefits might be ignored altogether. However, caution should be exercised in drawing conclusions, because these benefits (experience of new technology, employee morale, reduced floor space, reduced after sale costs) are not considered to be particularly important by practitioners (see table 5).

Two further questions were asked in relation to recognition of the benefits of AMT and the possibility of implementing AMT investment on "strategic" grounds only (see table 9).

These results again offer broad support for hypothesis 9. Practitioners confirm that some potential benefits are not taken into account because they are difficult to express in financial terms and they disagree with the proposition that AMT investment might be approved on nonfinancial grounds alone. Again, however, caution should be exercised in assessing the strength of these views. If some benefits are unimportant it hardly matters that they are ignored, and, just because AMT investment cannot normally be justified on non-financial grounds alone, it does not necessarily follow that AMT is especially difficult to justify.

\section{Discussion}

The survey indicates that investment projects are affected by three groups of factors: financial return measures, non-financial criteria, and risk measures. This conclusion is based on the perceived importance of at least some of the measures or criteria within each group of factors. For example, the payback period, a financial measure, was judged important or extremely important by $75 \%$ of respondents. Eighty seven percent of respondents considered the 'quality and reliability of outputs', a non-financial criteria, important or extremely important. 'Sensitivity 
analysis', a risk measure, was considered as important or extremely important by $77 \%$ of respondents. The following discussion is structured around these three groups of factors.

\subsection{Financial return measures}

The evaluation of projected financial return (Hypotheses 2, 4, 5, and 8) remains important. All the measures of financial return are important, with the 'naive' techniques, ROI and payback period, being seen as marginally more important than the sophisticated discounting techniques. This finding is consistent across all three groups of companies (non-AMT, less-integrated, and fully-integrated AMT) so hypothesis 5 that: the sophistication of the project affects the choice of financial technique, is rejected. This finding is consistent with those of Woods et al (1985), Lefley (1994) and Chen (1995).

It would be tempting to conclude that investment evaluation is still undertaken in a relatively naive manner in many companies. However, the continuing importance of payback (see also, Klammer, 1970; Woods et al., 1985; Schall et al., 1987; Pike, 1982, 1988 and 1996; Drury et al., 1993; and Lefley, 1994) and ROI should not be taken out of context. The survey results lead to the rejection of hypothesis 2- that less reliance is placed on economic/financial analysis in justification of AMT investments than for non-AMT investments. In fact, the results indicate that all the measures of financial performance are seen as important, whether evaluating AMT or non-AMT investments. In addition, most respondents disagreed with the proposition that: ' it is possible to implement an AMT investment proposal based only on potential non-financial benefits.' It is clear that financial analysis is important, a range of financial indicators is usually employed and most of these indicators are seen as important (discounted payback period being a possible exception).

While hypothesis 5 concentrated on the choice of technique in relation to AMT, hypothesis 8 concentrated on criteria. Hypothesis 8, that the same criteria are applied to AMT as to other investments, was supported. A picture of practice emerges where the same financial techniques and financial criteria are applied to all investments whether AMT or not. As other researchers have found, stringent criteria are often applied in practice and this survey supports previous findings with short payback periods and relatively high discount rates being the norm.

It would be logical to conclude that AMT investment proposals are penalised by these practices, supporting Kaplan's (1986) question 'Must AMT be justified by faith alone?' and Lefley's (1994, p. 2758) assertion that: '... the use of [the] PB method of investment appraisal practically guarantees rejection of AMT projects ...'. Lefley continued: ' ... the payback method, with its 'short' payback period, is inappropriate for projects such as AMT where the capital expenditure is spread over a number of years, and the returns do not fully materialise until well into the life or [of] the project.'

However, care must be exercised in reaching such conclusions because respondents did not generally agree with the proposition: 'It is difficult to get AMT investment proposals approved because of stringent financial criteria.' Traditional techniques are used and stringent financial criteria applied but this does not necessarily mean that AMT proposals are more difficult to approve than other investment proposals. One could speculate about the reasons for this finding. Perhaps, contrary to expectations, AMT investments actually meet the criteria laid down; or financial analysis is seen as a post hoc exercise to confirm an investment decision made on other grounds; or the apparently high return demanded is offset when non-financial factors are taken into account. This issue is considered next.

\subsection{Non-financial criteria}

Hypotheses 1, 3, and 9 relate to the evaluation of non-financial criteria in AMT investments. Hypothesis 1 postulates increasing use of 'strategic' analysis and hypothesis 3 suggested that a wide range of intangible benefits would be incorporated in such analysis. The first hypothesis was supported and there was restricted support for hypothesis 3. 
There was some evidence in support of hypothesis 9: that AMT investment is difficult to justify because of failure to recognise all their intangible or non-financial benefits. Respondents tended to agree that 'some of the potential benefits of AMT are not taken into account because they are difficult to express in financial terms.' However, this is not conclusive, because the omission of criteria such as 'improved company image', 'employee morale' and 'experience with new technology' is not significant if such issues are judged unimportant- and many respondents did not consider these 'benefits' to be important. It was surprising that 'employee morale' was judged unimportant because other researchers (for example, Accola, 1994 and Mensah and Miranti, 1989) have seen this as an important motivation for investing in AMT.

Table 6 suggests that at least eight non-financial criteria (or intangible factors) are considered important in the evaluation process. Further analysis of the importance of intangible factors across the three groups of companies indicated that these factors were seen as more important by fully-integrated companies than by the other two groups (non-AMT and less-integrated companies). The mean scores for almost all the intangible factors were higher for fully-integrated companies than for the other two groups of companies (see table 6) and this supports the view of Meredith and Hill (1987) who argued that the justification of higher levels of automation usually needs more attention to intangible factors relative to economic justification. For four nonfinancial factors the Kruskal-Wallis one-way ANOVA indicated significant differences among the three groups of companies and these factors may be the key 'drivers' behind many AMT investments. Additionally, the intangible factor 'requirements of customers', is very important in all groups of companies and indicates that firms should pay considerable attention to market research during investment appraisal.

The importance of intangible factors in investment appraisal is confirmed by this survey and specific factors are identified as important by the majority of respondents.

\subsection{Risk measures (hypotheses 6 and 7)}

The survey results indicate that sensitivity analysis is the most important technique for dealing with investment project risk. This finding is consistent with the findings of Klammer et al. (1991), Pike (1988) and Ho and Pike (1991).

A significant difference ${ }^{4}$ was found in the importance of sensitivity analysis among the three groups of companies. It was less important in both less-integrated and fully-integrated companies than non-AMT companies. This finding is consistent with that of Lefley (1994) who found a reduction in the use of sensitivity analysis in assessing AMT investment project risk.

The widespread use of sensitivity analysis as evidenced by the current survey might be attributed to its simplicity and the availability of computer packages which can help in applying it in practice. Strictly, sensitivity analysis is not a technique of risk analysis at all, it merely describes the sensitivity of key factors through their effect on the profitability of a project. It gives an indication of the most sensitive variables but not their probability of occurrence. A further limitation is the consideration of only one variable at once. (This could be overcome by use of computer based simulation but this technique was considered important by only $11 \%$ of respondents). This does not mean the technique is irrelevant but it does mean that it should only be a first step in evaluating risk. Knowing the key sensitive factors, decision makers can then estimate their variability and more sophisticated methods of risk analysis can then be undertaken.

Adjusting the required PB period according to the riskiness of a project was judged either important or extremely important technique by only $40 \%$ of the respondents. This may appear

\footnotetext{
${ }^{4}$ At $8 \%$ level of significance
} 
inconsistent with the earlier findings of Lefley (1994) who found 71.5\% of respondents used this method. However, Lefley's respondents may use the technique without considering it especially important and, when this is taken into account, the results of the two surveys can easily be reconciled. The low percentage of respondents who consider adjusting the required payback period as an important way of reflecting project risk may seem inconsistent with the high importance given to payback as a financial appraisal technique but this provides evidence that decision makers separate the two issues of financial evaluation and risk assessment.

In this survey, $70 \%$ of respondents in the non-AMT companies required payback in 3 years or less while $76 \%$ and $83 \%$ of respondents in less-integrated and fully-integrated companies respectively required this payback period. If shorter payback is required for higher risk investments, it might be inferred that AMT investments are perceived to be riskier than other investments. A similar inference could be drawn from the finding that higher discount or hurdle rates are employed in both less-integrated and fully-integrated companies than in non-AMT companies. While only $41 \%$ of respondents used $16 \%$ or more as a hurdle rate in non-AMT companies, $53 \%$ and $60 \%$ of respondents used the same range in less-integrated and fullyintegrated companies respectively.

In general, the survey findings relating to risk analysis did not give a clear idea about how practitioners deal with investment risks. Only sensitivity analysis and the use of conservative cash flow estimates were considered important in dealing with risk by the majority of respondents. The most preferred theoretical methods in evaluating investment risk: probability analysis, CAPM and computer simulation, were judged to be important by very few respondents. Furthermore, when respondents were asked to indicate the importance of the three possible dimensions of risk suggested by Accola (1994) (the impact on company liquidity, the variability of the project outcome, and the possibility of massive loss) only the impact on company liquidity was rated important by over $50 \%$ of respondents.

\section{Conclusion}

A recurrent theme in the AMT literature is the strategic importance of such investments and hence the need for a wider analysis when appraising them. Many researchers have developed theoretical models designed to meet this perceived need by combining both financial and strategic analyses. Such models range from simple combination of multiple attribute scores (e.g. Parsaei and Wilhelm, 1989; Meredith and Suresh, 1986; Nelson, 1986) to the relatively sophisticated analytic hierarchy process (e.g. Wabalickis, 1988; Ghosh and Wabalickis, 1991; Putrus, 1990; Datta et al., 1992; O’Brien and Smith, 1993; Angelis and Lee, 1996) and the use of 'strategic cost management' analysis (e.g., Shank, 1996 and Carr and Tomkins, 1996).

The models in the literature usually either illustrate a particular algorithm (such as the analytic hierarchy process) or a particular theoretical perspective (such as Porter's strategic analysis). Whilst many models do not have clear justifications, there are now a number of themes in the AMT literature and these themes provided a basis for framing the hypotheses tested in this research.

The results suggest that AMT investment decisions in practice do involve increasingly 'strategic' analysis but not at the expense of economic or financial analysis. 'Intangible', 'strategic', benefits such as customer requirements and consistency with corporate strategy are important in investment decision making and four specific intangible benefits: 'quality and reliability of outputs', 'reduced lead-times', 'obtaining greater manufacturing flexibility', and 'reduced inventory levels' are of particular significance in justifying AMT.

Several measures of financial return are considered to be important in practice and most companies employ a 'package' of such measures (typically, payback, return on investment and discounted cash flow measures) when evaluating investment projects. Practitioners appear to make no distinction between AMT and other investments either in the techniques employed or in 
the criteria used in decision making. The financial criteria employed seem quite stringent with payback period of less than 3 years and discount/hurdle rate in excess of $10 \%$ per annum being common.

It might seem logical to conclude that the difficulties of incorporating intangible benefits and omission of some benefits together with stringent financial criteria would penalise AMT investment proposals. There is evidence that this may be so but caution should be exercised in drawing conclusions because practitioners do not appear to regard, some benefits (such as 'improved company image', 'employee morale' and 'experience with new technology') as important - so their omission may not matter. And practitioners do not perceive gaining approval for AMT investments to be more difficult than other investment proposals.

The findings provide practitioner support for a number of normative proposals in the literature. Models which attempt to combine 'financial' and 'strategic' analyses would be favoured as would the inclusion of several financial measures and certain, specific, 'intangible' benefits. Conversely, models which concentrate solely on financial or strategic analysis would not be favoured and some 'intangible' benefits routinely incorporated in examples in the literature would not normally be regarded as important by practitioners.

The survey suggests that the treatment of risk in practice is relatively naive. Sophisticated techniques of risk analysis are not employed for AMT (or any other) investment project and the only really popular technique is sensitivity analysis. Here a significant difference between companies was found with the technique being rated most important by non-AMT companies!

In general the survey results provide confirmation of work by field researchers such as Nixon (1995) and Slagmulder and Bruggeman (1992). Typically, practitioners adopt holistic approaches incorporating both financial and strategic analyses in the evaluation of AMT investment proposals. There is also support for Shank's 'strategic cost management' (SCM) analysis. Shank (1996) identified three SCM themes which 'should' be considered in AMT appraisal: value chain analysis, cost driver analysis and competitive advantage analysis. These three themes can readily be discerned in practitioners concern with: quality and reliability of outputs and requirements of customers (value chain analysis); greater manufacturing flexibility, reduced lead-times and reduced inventory levels (value chain analysis and cost driver analysis); and keeping up with competition (competitive advantage analysis).

While this survey highlights practitioner concern with financial and strategic analyses it does not necessarily indicate that such analyses are undertaken in a systematic manner. This provides motivation for further research into the development of normative models which practitioners would find acceptable. Multiple attribute, analytic hierarchy process and strategic cost management models hold promise for this line of research.

The survey also suggests that the treatment of risk in practice would be a suitable topic for further research. A series of interviews with nine of the survey respondents was undertaken in order to both confirm the survey findings and to further investigate this topic. These interviews did support the survey findings and, additionally, revealed that practitioners were not so concerned with measuring project risk as with minimising it. The normative recommendations in the literature appear to find little favour with practitioners and the development of models which would be acceptable to practitioners and the (empirical) identification of 'best practice' would also appear to be fruitful area for further research.

\section{References}

Abdel-Kader, M. G., 1997, Investment decisions in advanced manufacturing systems: a review and identification of research areas, In: Issues in Accounting and Finance, Atrill, P., and Lindley, L., (eds.), Ashgate, Aldershot, pp.189-216.

Accola, W. L., 1994, Assessing risk and uncertainty in new technology investments, Accounting Horizons, 8, 19-35. 
Accola, W., Agrawal, S., and Holsapple, C., 1995, Adaptive decision support systems for evaluating risk and uncertainty in capital investment decisions: opportunities for future research, Managerial Finance, 21, pp. 1-16.

Angelis, D., and Lee, C., 1996, Strategic investment analysis using activity based costing concepts and analytical hierarchy process techniques, International Journal of Production Research, 34, pp. 1331-1345.

Ashenbrenner, K., 1984, Moment-versus dimension-oriented theories of risky choice: a (fairly) general test involving single-peaked preferences, Journal of Experimental Psychology: Learning, Memory, and Cognition, 10, pp. 513-535.

Chen, S., 1995. An empirical examination of capital budgeting techniques: impact of investment types and firm characteristics, The Engineering Economist, 40, 145-170.

Datta, V., Sambasivarao, K., Kodali, R., and Deshmukh, S., 1992, Multi-attribute decision model using the analytic hierarchy process for the justification of manufacturing systems, International Journal of Production Economics, 28, pp. 227-234.

Davis, E., and Pointon, J., 1994, Finance and the Firm: An Introduction to Corporate finance, 2nd ed., Oxford University Press, Oxford.

Drury, C., Braund, S., Osborne, P. and Tayles, M., 1993. A Survey of Management Accounting Practices in UK Manufacturing Companies, London, The Chartered Association of Certified Accountants, Chapter 6, 41-48.

Dugdale, D., and Jones, C., 1995, Financial justification of advanced manufacturing technology, In: Issues in Management Accounting, 2nd ed., Ashton, D., Hopper, T., and Scapens, R. (eds.), Prentice Hall, London, pp. 191-213.

Elango, B., and Meinhart, W., 1994, Selecting a flexible manufacturing system - a strategic approach, Long Range Planning, 27, pp. 118-126.

Ghosh, B., and Wabalickis, R., 1991, A comparative analysis for the justification of future manufacturing systems, International Journal of Operations \& Production Management, 9, pp. 4-23.

Gibbons, J., 1993. Nonparametric Statistics: An Introduction, London, Sage Publications.

Hastie, K. L., 1974, One businessman's view of capital budgeting, Financial Management, Winter, 36-44.

Haynes,W.W., and Solomon Jr. M. B., 1962, A misplaced emphasis in capital budgeting, Quarterly Review of Economics and Business, February, 39-46.

Hendricks, J., 1988. Applying cost accounting to factory automation, Management accounting (USA), December, 24-30.

Ho, S., and Pike, R., 1991. Risk analysis in capital budgeting contexts: simple or sophisticated?, Accounting and Business Research, 21, 227-238.

Ho, S., and Pike, R., 1992. Adoption of probabilistic risk analysis in capital budgeting and corporate investment, Journal of Business Finance and Accounting, 19, 387-405.

Hundy B., and Hamblin, D., 1988, Risk and assessment of investment in new technology, International Journal of Production Research, 26, pp. 1799-1810.

Kalyebara, B., 1996. The determination and use of the hurdle rate in capital budgetingAustralian experience, Paper Presented at the National Conference of The British Accounting Association, Cardiff, 27-29 March.

Kaplan, R., and Atkinson, A., 1989. Advanced Management Accounting, 2nd ed., New Jersey, Prentice-Hall, Englewood Cliffs, Chapter12, 473-521.

Kaplan, R., 1986, Must CIM be justify by faith alone?, Harvard Business Review, March-April, pp. 87-93.

King, P., 1975, Is the emphasis of capital budgeting theory misplaced?, Journal of Business Finance and Accounting, 2, 69-82. 
Klammer, T., Koch, B., and Wilner, N., 1991. Capital budgeting practices- a survey of corporate use, Journal of Management Accounting Research, 3, 113-130.

Klammer, T., 1970. Empirical evidence of the adoption of sophisticated capital budgeting techniques, Journal of Business, July, 387-397.

Lefley, F., 1994. Capital investment appraisal of advanced manufacturing technology, International Journal of Production research, 32, 2751-2776.

Lumby, S., 1995. Investment Appraisal and Financial Decisions, 5th ed., London, Chapman \& Hall.

Medearis, H. D., Helms, M. M. and Ettkin, L. P., 1990. Justifying flexible manufacturing systems (FMS) from a strategic perspective, Manufacturing Review, 3, 219-223.

Mensah, Y. M., and Miranti, P. J., 1989. Capital expenditure analysis and automated manufacturing systems: a review and synthesis, Journal of Accounting Literature, 8, 181-207.

Meredith, J. R., and Hill, M., 1987. Justifying new manufacturing systems: a managerial approach, Sloan Management Review, Summer, 49-61.

Meredith, J. R., and Suresh, N. C., 1986. Justification techniques for advanced manufacturing technologies, International Journal of Production Research, 24, 1043-1057.

Nelson, C., 1986, A scoring model for flexible manufacturing systems project selection, European Journal of Operational Research, 24, pp. 346-359

Nixon, B., 1995. Technology investment and management accounting practice, British Journal of Management, 6, 271-288.

O'Brien, C., and Smith, S., 1993, Design of the decision process for strategic investment in advanced manufacturing systems, International Journal of Production Economics, 30-31, pp. 309-322.

Park, C., and Son, Y., 1988, An economic evaluation model for advanced manufacturing systems, The Engineering Economist, 34, pp. 1-26.

Parsaei, H., and Wilhelm, M., 1989, A justification methodology for automated manufacturing technologies, Computers and Industrial Engineering, 16, pp. 363-373.

Pike, R., and Dobbins, R., 1986. Investment Decisions and Financial Strategy, Oxford, Philip Allan.

Pike, R., and Wolfe, M., 1988. Capital Budgeting for the 1990's, London, The Chartered Institute of Management Accountants (CIMA).

Pike, R., Sharp, J., and Price, D., 1989. AMT investment in the larger UK firm, International Journal of Operations and Production Management, 9, 13-26.

Pike, R., 1982. Capital Budgeting in the 1980s: A major Survey of the Investment Practices in Large Companies, London, The Institute of Cost and Management Accountants.

Pike, R., 1988a. An empirical study of the adoption of sophisticated capital budgeting practices and decision-making effectiveness, Accounting and Business Research, 18, 341-351.

Pike, R., 1996. A longitudinal survey on capital budgeting practices, Journal of Business Finance \& Accounting, 23, 79-92.

Primrose, P., and Leonard, R., 1987, Automation needs no justification, New Scientist, 115, 3 September, pp. 60-62.

Primrose, P. L., 1991. Investment in Manufacturing Technology, London, Chapman \& Hall.

Putrus, R., 1990, Accounting for intangible in integrated manufacturing, Information Strategy: The Executives Journal, 6, pp. 25-30.

Schall, L. D., Sundem, G. L., and Geijsbeek, W. R., Jr., 1978. Survey and analysis of capital budgeting methods, The Journal of Finance, March, 281-287.

Schoemaker, P., 1979, The role of statistical knowledge in gambling decisions: moment vs risk dimension approaches, Organizational Behavior and Human Performance, 24, pp. 1-17. 
Shank, J. 1996, Analysing technology investments-from NPV to strategic cost management (SCM), Management Accounting Research, 7, pp. 185-197.

Siegel, S. and Castellan, N., Jr., 1988. Nonparametric Statistics for the Behavioral Sciences, 2nd edition, New York, McGraw-Hill Book Co.

Slagmulder, R. And Bruggeman, W., 1992. Justification of strategic investment in flexible manufacturing technology, Integrated Manufacturing Systems, 3, 4-14.

Slagmulder, R., Bruggeman, W., and Wassenhove, L., 1995, An empirical study of capital budgeting practices for strategic investments in cim technologies, International Journal of Production Economics, 40, pp. 121-152.

Srinivasan, V., and Millen, R., 1986, Evaluating flexible manufacturing systems as a strategic investment, Proceedings of the Second ORSA/TIMS Conference on Flexible Manufacturing Systems: Operations Research Models and Applications, Stecke, K., and Suri, R. (eds.), Elsevier Science Publishers, Amsterdam, pp. 83- 93.

Tannous, G. F., 1996. Capital budgeting for volume flexible equipment, Decision Science, 27,157-184.

Van Cauwenbergh, A., Durinck, E., Martens, R., Laveren, E., and Bogaert, I., 1996, On the role and function of formal analysis in strategic investment decision processes: results from an empirical study in belgium, Management Accounting Research, 7, pp. 169-184.

Wabalickis, R., 1988, Justification of FMS with the analytic hierarchy, Journal of Manufacturing Systems, 7, pp. 175-182.

Walker, M. C. and Klammer, T., 1984. The continuing increase in the use of sophisticated capital budgeting techniques, California Management Review, 27, 137-148.

Woods, M., Pokorny, M., Lintner, V., and Blinkhorn, M., 1985. Appraising investment in new technology: the approach in practice, Management Accounting (UK), October, 42-43. 


\section{Table 1}

Summary of the dependent variables

Importance of financial analysis

Where financial analysis implies the use of techniques such as payback, return on investment and discounted cash flow methods.

Importance of intangible benefits

Typical intangible benefits being: flexibility, delivery performance, improved quality/

reliability, etc.

Sophistication of financial analysis

Importance of risk analysis

Sophistication of risk analysis

Financial criteria
Where discounted cash flow techniques are seen as more sophisticated than payback and simple return on investment calculations.

Where risk analysis implies the use of techniques such as sensitivity analysis, discrete probability analysis, simulation, the capital asset pricing model (CAPM) etc.

Where simulation and CAPM are seen as more sophisticated than sensitivity analysis and simple adjustments to payback periods and/or hurdle rates.

Related to stipulated parameters such as required payback period and/ or hurdle rate. 


\section{Table 2}

Summary of the hypotheses development

\begin{tabular}{|c|c|c|}
\hline Underlying theme & Relevant literature & Hypotheses \\
\hline $\begin{array}{l}\text { As an investment becomes more integrated and } \\
\text { strategic' the balance of analysis 'should' } \\
\text { change away from traditional methods towards } \\
\text { more 'strategic' evaluation. }\end{array}$ & $\begin{array}{l}\text { Meredith and Suresh } \\
\text { (1986), Srinivasan and } \\
\text { Millen (1986), Parsaei } \\
\text { and Wilhelm (1989), } \\
\text { O’Brien and Smith } \\
\text { (1993), Accola (1994), } \\
\text { Angelis and Lee } \\
\text { (1994). }\end{array}$ & $\begin{array}{l}\text { H1: Companies rely more on strategic decision } \\
\text { criteria for AMT investments than for non-AMT } \\
\text { investments. } \\
\text { H2: Less reliance is placed on financial analysis for } \\
\text { AMT investments than for non-AMT } \\
\text { investments. }\end{array}$ \\
\hline $\begin{array}{l}\text { AMT investments, typically, generate a range } \\
\text { of 'intangible’ benefits which are difficult to } \\
\text { evaluate using traditional economic/financial } \\
\text { analyses. }\end{array}$ & $\begin{array}{l}\text { Putrus (1990), Datta et } \\
\text { al. (1992), O’Brien and } \\
\text { Smith (1993), Accola } \\
\text { (1994). }\end{array}$ & $\begin{array}{l}\text { H3: A wide range of intangible benefits become } \\
\text { important in the justification of AMT (as } \\
\text { opposed to non-AMT) investment. }\end{array}$ \\
\hline $\begin{array}{l}\text { 'Sophisticated' methods of investment } \\
\text { appraisal have become increasingly } \\
\text { widespread, especially in large companies. }\end{array}$ & $\begin{array}{l}\text { Klammer et al. (1991), } \\
\text { Pike (1988a and } \\
\text { 1988b), Chen (1995), } \\
\text { Schall et al. (1987), } \\
\text { Drury et al. (1993). }\end{array}$ & $\begin{array}{l}\text { H4: Sophisticated, DCF, methods of investment } \\
\text { appraisal are now more important than } \\
\text { unsophisticated methods in large companies. }\end{array}$ \\
\hline $\begin{array}{l}\text { More sophisticated users of new technology are } \\
\text { likely to employ more sophisticated techniques } \\
\text { of evaluation. }\end{array}$ & Woods et al. (1985). & $\begin{array}{l}\text { H5: The sophistication of the financial evaluation } \\
\text { technique used increases with the sophistication } \\
\text { of the investment project being evaluated: from } \\
\text { non-AMT to fully integrated AMT. }\end{array}$ \\
\hline
\end{tabular}

(Continued on next page) 
Table 2 (continued)

\begin{tabular}{|c|c|c|}
\hline Underlying these & Relevant literature & hypotheses \\
\hline $\begin{array}{l}\text { Project risk has a number of separate } \\
\text { underlying 'dimensions' which 'should' be } \\
\text { taken into account. }\end{array}$ & Accola (1995) & $\begin{array}{l}\text { H6: Practitioners consider three risk 'dimensions' to } \\
\text { be important: impact of the project on company } \\
\text { liquidity, variability of project outcomes, and } \\
\text { possibility of massive loss. }\end{array}$ \\
\hline $\begin{array}{l}\text { The large outlays involved in AMT investment } \\
\text { and the delayed benefits from such } \\
\text { investments make AMT investments risky and } \\
\text { therefore sophisticated risk analysis techniques } \\
\text { 'should' be employed in their evaluation. }\end{array}$ & $\begin{array}{l}\text { Ho and Pike (1991 and } \\
\text { 1992), Walker and } \\
\text { Klammer (1984). }\end{array}$ & $\begin{array}{l}\text { H7: More sophisticated treatments of risk are } \\
\text { employed in the evaluation of AMT investment } \\
\text { as opposed to non-AMT investments. }\end{array}$ \\
\hline $\begin{array}{l}\text { Traditional economic/ financial analysis } \\
\text { penalise AMT investment proposals through } \\
\text { omission of 'intangible' benefits and use of } \\
\text { stringent discount rate and payback criteria. }\end{array}$ & $\begin{array}{l}\text { Kaplan (1986), Kaplan } \\
\text { and Atkinson (1989), } \\
\text { Dugdale and Jones } \\
\text { (1995), Abdel-Kader } \\
\text { (1997). }\end{array}$ & $\begin{array}{l}\text { H8: The same financial criteria are applied to AMT } \\
\text { investments as other (non-AMT) investments. } \\
\text { H9: AMT investments are difficult to justify because } \\
\text { of failure to recognise all their "strategic" or } \\
\text { "intangible" benefits. }\end{array}$ \\
\hline
\end{tabular}


Table 3

Types of AMT projects invested in

\begin{tabular}{lcc}
\hline & No. & $\%$ \\
\hline Computer Aided Design (CAD) & 65 & 86 \\
Computer Numerical Control (CNC) & 48 & 63 \\
Automated Material Handling (AMH) & 43 & 57 \\
Computer Aided Manufacturing (CAM) & 42 & 55 \\
Robotics & 33 & 43 \\
Flexible Manufacturing Systems(FMS) & 32 & 42 \\
Computer Integrated Manufacturing (CIM) & 27 & 36 \\
\hline
\end{tabular}

Table 4

Level of AMT in the company

\begin{tabular}{lll}
\hline & No. & $\%$ \\
\hline Non-AMT companies & 23 & 23.2 \\
Less integrated AMT companies & 33 & 33.3 \\
Fully integrated AMT companies & 43 & 43.4 \\
\hline
\end{tabular}


Table 5

A Comparison of Investment Decision Factors for the Three Group of Companies

\begin{tabular}{lcccccc}
\hline & \multicolumn{2}{c}{ Non-AMT } & \multicolumn{2}{c}{ Less integrated } & \multicolumn{2}{c}{ Fully integrated } \\
\cline { 2 - 7 } & Mean & Std. dev. & Mean & Std. dev. & Mean & Std. dev. \\
\hline \multirow{2}{*}{ Panel A: Financial appraisal techniques } & & & & & & \\
Return on Investment & 4.09 & 1.11 & 3.83 & 1.31 & 4.17 & 1.07 \\
Payback & 3.73 & 1.20 & 4.23 & 0.77 & 4.06 & 0.96 \\
Discounted Payback & 3.10 & 1.34 & 3.42 & 1.28 & 3.31 & 1.37 \\
Net Present Value & 3.50 & 1.36 & 3.55 & 1.27 & 3.84 & 1.21 \\
Internal Rate of Return & 3.70 & 1.42 & 3.78 & 1.31 & 4.06 & 0.94 \\
\hline
\end{tabular}

Panel B: Non-financial investment criteria

\begin{tabular}{lllllll} 
Quality and reliability of outputs & 4.17 & 0.94 & 4.13 & 0.87 & 4.63 & 0.49 \\
Requirements of customers & 4.00 & 1.07 & 4.13 & 0.71 & 4.40 & 0.77 \\
Consistency with corporate strategy & 4.00 & 0.95 & 4.03 & 0.71 & 4.36 & 0.74 \\
Obtaining greater manufacturing & 3.86 & 1.04 & 3.97 & 0.91 & 4.24 & 0.97 \\
flexibility & & & & & & \\
Reduced lead-times & 3.52 & 0.93 & 3.93 & 1.01 & 4.17 & 0.85 \\
Keeping up with competition & 3.50 & 0.80 & 3.78 & 1.18 & 4.05 & 0.94 \\
Reduced inventory levels & 3.38 & 1.12 & 3.70 & 0.99 & 3.78 & 1.01 \\
The ability to expand in the future & 3.30 & 1.13 & 3.52 & 0.85 & 3.63 & 1.26 \\
Improved company image & 3.14 & 0.77 & 2.97 & 0.93 & 2.95 & 1.15 \\
Employee morale & 2.91 & 0.97 & 2.94 & 0.85 & 2.84 & 0.86 \\
Experience with new technology & 2.78 & 0.80 & 2.93 & 1.05 & 2.72 & 1.09 \\
\hline Panel C: Risk analysis techniques & & & & & & \\
Sensitivity analysis & & & & & & \\
Use of conservative cash flow forecasts & 3.36 & 0.95 & 3.71 & 1.24 & 4.24 & 0.89 \\
Adjust required payback period & 2.86 & 1.05 & 3.27 & 1.22 & 3.37 & 0.96 \\
Adjust required return on investment & 2.80 & 1.31 & 3.35 & 1.19 & 3.13 & 1.31 \\
Adjust discount rate & 2.67 & 1.06 & 2.77 & 1.27 & 3.03 & 1.32 \\
Computer simulation & 2.05 & 0.97 & 1.81 & 1.03 & 2.19 & 0.98 \\
Capital asset pricing model & 2.06 & 1.16 & 1.50 & 0.76 & 2.00 & 1.27 \\
Probability analysis & 2.30 & 1.22 & 1.65 & 0.88 & 2.19 & 1.08 \\
\hline Panel D: Accola's risk aspects & & & & & & \\
Impact on company liquidity & 3.62 & 1.02 & 3.17 & 1.50 & 3.48 & 1.19 \\
Variability of project outcome & 3.70 & 1.13 & 2.65 & 1.37 & 3.65 & 1.05 \\
Possibility of massive loss & 3.68 & 1.29 & 2.70 & 1.58 & 3.07 & 1.34 \\
\hline & & & & & & \\
\hline
\end{tabular}


Table 6

Results of Kruskal-Wallis One-way ANOVA for Investment Decision Factors

\begin{tabular}{|c|c|c|c|c|c|c|}
\hline & \multicolumn{3}{|c|}{ Mean Rank } & \multirow{2}{*}{$\begin{array}{l}\text { Kruskal-Wallis } \\
\text { Statistic }\end{array}$} & \multirow[t]{2}{*}{ D.F. } & \multirow[t]{2}{*}{ P-Value } \\
\hline & $\begin{array}{l}\text { Non- } \\
\text { AMT }\end{array}$ & $\begin{array}{c}\text { Less } \\
\text { integrated }\end{array}$ & $\begin{array}{c}\text { Fully } \\
\text { integrated }\end{array}$ & & & \\
\hline \multicolumn{7}{|c|}{ Panel A: Financial appraisal techniques } \\
\hline $\begin{array}{l}\text { Return on Investment } \\
\text { Payback } \\
\text { Discounted Payback } \\
\text { Net Present Value } \\
\text { Internal Rate of Return }\end{array}$ & $\begin{array}{l}44.11 \\
40.39 \\
37.17 \\
40.67 \\
39.67 \\
\end{array}$ & $\begin{array}{l}39.83 \\
50.65 \\
42.38 \\
41.17 \\
40.20 \\
\end{array}$ & $\begin{array}{l}46.16 \\
46.75 \\
41.21 \\
46.85 \\
43.54 \\
\end{array}$ & $\begin{array}{l}1.1827 \\
2.1210 \\
0.6614 \\
1.2582 \\
0.5006 \\
\end{array}$ & $\begin{array}{l}2 \\
2 \\
2 \\
2 \\
2\end{array}$ & $\begin{array}{l}.5536 \\
.3463 \\
.7184 \\
.5331 \\
.7786 \\
\end{array}$ \\
\hline \multicolumn{7}{|c|}{ Panel B: Non-financial investment criteria } \\
\hline $\begin{array}{l}\text { Quality and reliability of outputs } \\
\text { Requirements of customers } \\
\text { Consistency with corporate strategy } \\
\text { Obtaining greater manufacturing } \\
\text { flexibility }\end{array}$ & $\begin{array}{l}36.82 \\
47.17 \\
47.55 \\
31.26\end{array}$ & $\begin{array}{l}41.19 \\
44.20 \\
44.74 \\
44.45\end{array}$ & $\begin{array}{l}59.32 \\
53.65 \\
50.64 \\
55.17\end{array}$ & $\begin{array}{l}15.0012 \\
02.5874 \\
00.9561 \\
13.1440\end{array}$ & $\begin{array}{l}2 \\
2 \\
2 \\
2\end{array}$ & $\begin{array}{l}.0006 \\
.2743 \\
.6200 \\
.0140\end{array}$ \\
\hline Reduced lead-times & 32.33 & 45.53 & 54.46 & 10.8215 & 2 & .0045 \\
\hline Keeping up with competition & 53.15 & 44.87 & 46.26 & 01.5043 & 2 & .4713 \\
\hline Reduced inventory levels & 35.20 & 47.73 & 53.18 & 06.4487 & 2 & .0398 \\
\hline The ability to expand in the future & 42.77 & 43.89 & 52.77 & 03.1020 & 2 & .2120 \\
\hline Improved company image & 50.41 & 45.58 & 46.24 & 00.5187 & 2 & .7716 \\
\hline Employee morale & 47.68 & 47.10 & 44.13 & 00.3750 & 2 & .8290 \\
\hline Experience with new technology & 44.37 & 47.95 & 42.94 & 00.7098 & 2 & .7012 \\
\hline
\end{tabular}

(Continued on next page) 
Table 6 (Continued)

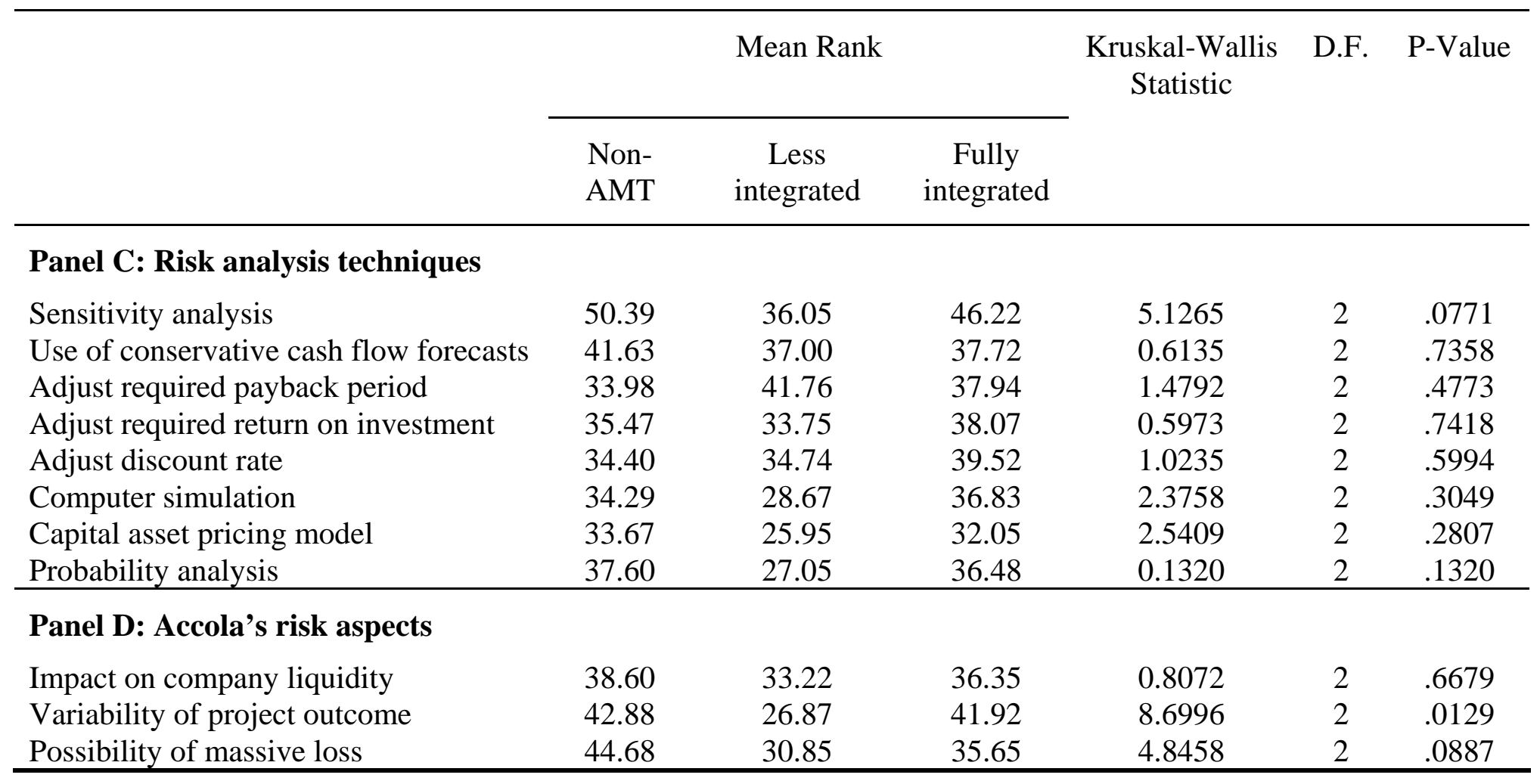


Table 7

The Most Frequently Used Payback Period in the Companies

\begin{tabular}{lcccc}
\hline & $\begin{array}{c}\text { Non } \\
\text { AMT } \\
(\mathrm{n}=20)\end{array}$ & $\begin{array}{c}\text { Less } \\
\text { integrated } \\
(\mathrm{n}=30)\end{array}$ & $\begin{array}{c}\text { Fully } \\
\text { integrated } \\
(\mathrm{n}=39)\end{array}$ & $\begin{array}{c}\text { All } \\
\text { companie }\end{array}$ \\
& & & & $\mathrm{s}$ \\
& $(\mathrm{n}=89)$ \\
\hline Less than 1 year & - & 3 & 3 & 2 \\
1 - 3 years & 70 & 73 & 80 & 75 \\
4 - 5 years & 25 & 23 & 15 & 20 \\
More than 5 years & 5 & - & 3 & 2 \\
\hline
\end{tabular}

Table 8

The Minimum Required Rates of Return or Discount Rates

\begin{tabular}{lcccc}
\hline & $\begin{array}{c}\text { Non } \\
\text { AMT } \\
(\mathrm{n}=17)\end{array}$ & $\begin{array}{c}\text { Less } \\
\text { integrated } \\
(\mathrm{n}=23)\end{array}$ & $\begin{array}{c}\text { Fully } \\
\text { integrated } \\
(\mathrm{n}=32)\end{array}$ & $\begin{array}{c}\text { All } \\
\text { companie }\end{array}$ \\
& & & & $\mathrm{s}$ \\
& $(\mathrm{n}=72)$ \\
\hline Less than 10\% & 6 & 17 & 9 & 11 \\
$10-15 \%$ & 53 & 30 & 31 & 36 \\
$16-20 \%$ & 41 & 22 & 44 & 36 \\
$21-25 \%$ & - & 22 & 10 & 11 \\
More than 25\% & - & 9 & 6 & 6 \\
\hline
\end{tabular}




\section{Table 9}

Opinions of Respondents Regarding to Three Propositions

\begin{tabular}{|c|c|c|c|c|c|c|c|}
\hline & \multicolumn{5}{|c|}{ \% of respondents } & \multirow[t]{2}{*}{ Mean } & \multirow[t]{2}{*}{ Std. dev. } \\
\hline & Score 1 & Score 2 & Score 3 & Score 4 & Score 5 & & \\
\hline $\begin{array}{l}\text { a. It is difficult to get AMT investment proposals } \\
\text { approved because of stringent financial } \\
\text { criteria. }\end{array}$ & 15 & 34 & 37 & 12 & 3 & 2.54 & 0.97 \\
\hline $\begin{array}{l}\text { b. Some of the potential benefits of AMT are not } \\
\text { taken into account because they are difficult to } \\
\text { express in financial terms. }\end{array}$ & 3 & 22 & 24 & 46 & 5 & 3.29 & 0.96 \\
\hline $\begin{array}{l}\text { c. It is possible to implement an AMT investment } \\
\text { proposal based only on potential non-financial } \\
\text { benefits. }\end{array}$ & 41 & 32 & 12 & 12 & 4 & 2.07 & 1.17 \\
\hline
\end{tabular}

Score 1: Strongly disagree, Score 2: Disagree, Score 3: Neutral, Score 4: Agree, Score 5: Strongly agree 
Table 10

Benefits of AMT Investments (\% of Respondents)

\begin{tabular}{lccc}
\hline & $\begin{array}{c}\text { Considered } \\
\text { financially }\end{array}$ & $\begin{array}{c}\text { Considered } \\
\text { non- } \\
\text { financially }\end{array}$ & $\begin{array}{c}\text { Not } \\
\text { considered } \\
\text { at all }\end{array}$ \\
\hline Reduced labor costs & 97 & 1 & 2 \\
Reduced material costs & 96 & 4 & - \\
Reduced inventories level & 92 & 6 & 2 \\
Reduced scrap and rework costs & 89 & 11 & - \\
Increased sales volume & 79 & 8 & 13 \\
Savings from less frequent set-ups & 69 & 23 & 8 \\
Increased manufacturing capacity & 52 & 38 & 10 \\
Improved product quality & 14 & 86 & - \\
Faster response to market needs & 11 & 86 & 3 \\
Consistency with corporate strategy & 10 & 78 & 12 \\
Improved competitive position & 20 & 77 & 3 \\
Greater manufacturing flexibility & 17 & 75 & 8 \\
Reduced lead times & 22 & 74 & 4 \\
Improved company image & - & 71 & 29 \\
Easier production scheduling & 12 & 65 & 23 \\
Retention of market share & 22 & 58 & 20 \\
Increased market share & 28 & 54 & 18 \\
Reduced after sale costs such as warranty & 41 & 27 & 32 \\
Floor space reduction & 27 & 39 & 34 \\
Effects on employee morale & 1 & 59 & 40 \\
Obtaining experience of new technology & 6 & 49 & 45 \\
\hline
\end{tabular}

